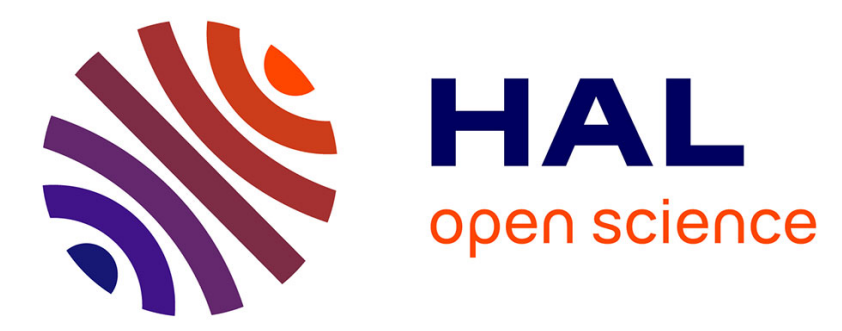

\title{
Development of spoke cavities for the EURISOL and EUROTRANS projects
}

G. Olry, J.-L. Biarrotte, S. Blivet, S. Bousson, C. Joly, T. Junquera, J. Lesrel, A.C. Mueller, H. Saugnac, P. Szott, et al.

\section{- To cite this version:}

G. Olry, J.-L. Biarrotte, S. Blivet, S. Bousson, C. Joly, et al.. Development of spoke cavities for the EURISOL and EUROTRANS projects. 12th International Workshop on RF Superconductivity, Jul 2005, Ithaca, United States. pp.201-204, 10.1016/j.physc.2006.03.116 . in2p3-00105516

\section{HAL Id: in2p3-00105516 https://hal.in2p3.fr/in2p3-00105516}

Submitted on 11 Oct 2006

HAL is a multi-disciplinary open access archive for the deposit and dissemination of scientific research documents, whether they are published or not. The documents may come from teaching and research institutions in France or abroad, or from public or private research centers.
L'archive ouverte pluridisciplinaire HAL, est destinée au dépôt et à la diffusion de documents scientifiques de niveau recherche, publiés ou non, émanant des établissements d'enseignement et de recherche français ou étrangers, des laboratoires publics ou privés. 


\title{
DEVELOPMENT OF SPOKE CAVITIES FOR THE EURISOL AND EUROTRANS PROJECTS.
}

\author{
G. Olry", J-L. Biarrotte, S. Blivet, S. Bousson, C. Joly, T. Junquera, J. Lesrel, A.C. Mueller, H. \\ Saugnac, P. Szott, CNRS/IN2P3, IPN Orsay, France.
}

E. Zaplatin, FZJ, Juelich, Germany.

\begin{abstract}
IPN Orsay is strongly involved within the EURISOL and EUROTRANS projects, especially collaborating to the overall design of their linac architecture. Since a few years, main part of the R\&D work is dedicated to the development of superconducting spoke cavities and their associated components (RF coupler, tuning system horizontal cryomodule...).

Following the very promising results obtained with our first single-spoke prototype (2-gap, $352 \mathrm{MHz}$, beta 0.35), a new prototype has been designed and fabricated (2-gap, $352 \mathrm{MHz}$, beta 0.15) in order to be integrated in a future linac. The mechanical and RF tests, done on this prototype, are presented. Then, an overview of the latest beam dynamics calculations performed to design a linac using spoke cavities will be described.
\end{abstract}

\section{BETA 0.35 SINGLE-SPOKE CAVITY}

This prototype has shown very promising RF performances: Eacc $\max =16.2 \mathrm{MV} / \mathrm{m}$ at $2 \mathrm{~K}$ (which corresponds to a voltage gain of 3.24 MV). More details of the measurements and results done at $4.2 \mathrm{~K}$ and $300 \mathrm{~K}$ temperatures are presented in the proceedings [1] and [2].

\section{Lorentz force detuning}

The static Lorentz force detuning factor has been measured several times during the cold tests. The cavity beam tubes were fixed every time. $\mathrm{K}_{\text {Lorentz measured }}$ (in $\left.\mathrm{Hz} /(\mathrm{MV} / \mathrm{m})^{2}\right)=-5.72,-6.94,-6.36,-6.68,-5.60$ and -7.30 at $4.2 \mathrm{~K}$ and -8.91 at $2 \mathrm{~K}$. Thanks to Evgeny Zaplatin from Forschungszentrum Jülich (FZJ), we have compared these experimental data with the one calculated with ANSYS. He found $\mathrm{K}_{\text {Lorentz calculated }}=-5.49 \mathrm{~Hz} /(\mathrm{MV} / \mathrm{m})^{2}$, using the same boundary conditions (i.e. both beam tubes fixed) and a 3-mm uniform thickness for all cavity walls. This result fits well the measurements, as for the other calculations he performed for the beta 0.15 spoke cavity (next §) and the beta 0.12 Quarter-Wave Resonator [3].

\section{BETA 0.15 SINGLE-SPOKE CAVITY}

Since 2002, the design of this second prototype has changed thanks to the experience gained on the beta 0.35 cavity. For instance, we chose a new RF port location and a new stiffening system $[4,1,2]$. The cavity has been

\footnotetext{
\#olry@ipno.in2p3.fr
}

built this year by the Cerca company within 7 months. Figure 1 shows the cavity after the final welding.

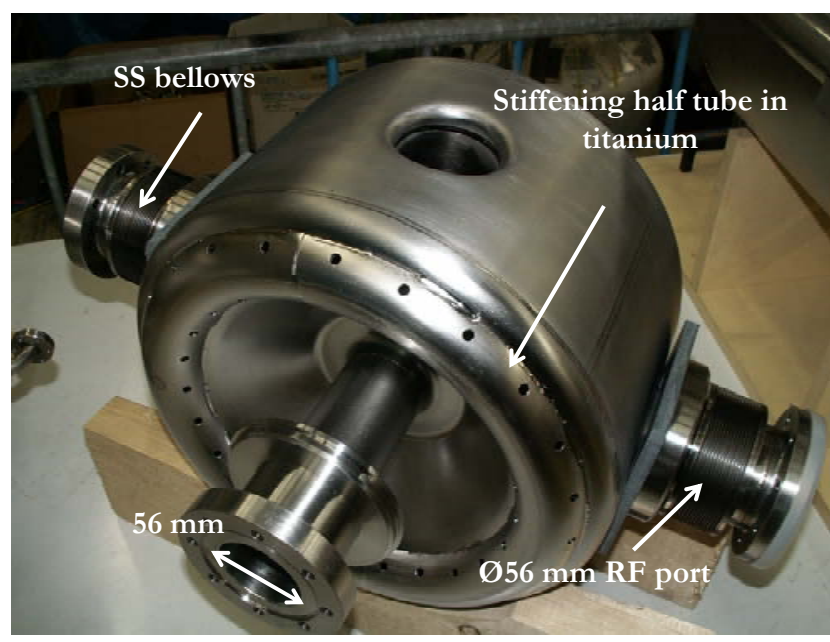

Figure 1: Beta 0.15 spoke cavity made of RRR250, 3-mm thick, niobium sheets from TokyoDenkaï (Japan).

\section{RF parameters}

The main RF parameters are presented in Table 1. New calculations have been performed using Microwave Studio (MWS) and have shown some discrepancies as compared to the previous ones performed with MAFIA (for instance, $-30 \%$ for the Qo value calculated with MWS). We did not yet investigate in details the reason why but it seems that the new modeller of MWS describes more precisely the geometry and gives more accurate values of the peak surface electric and magnetic fields.

Table 1: RF parameters of $\beta 0.15$ spoke cavity

\begin{tabular}{|c|c|c|}
\hline & MAFIA & MWS \\
\hline $\mathrm{Q}_{0}{ }^{\mathrm{a}}(@ \mathrm{4} .2 \mathrm{~K})$ & $1.36 \mathrm{E}+9$ & $1.76 \mathrm{E}+9$ \\
$(@ 2 \mathrm{~K})$ & $6.23 \mathrm{E}+9$ & $8.18 \mathrm{E}+9$ \\
\hline $\mathrm{G}[\Omega]$ & 67 & 89 \\
\hline Epeak/Eacc & $\begin{array}{c}3.32^{\mathrm{b}} \\
6.74^{\mathrm{c}}\end{array}$ & $\begin{array}{c}3.24^{\mathrm{b}} \\
6.56^{\mathrm{c}}\end{array}$ \\
\hline Bpeak/Eacc [mT/MV/m] & $\begin{array}{c}7.14^{\mathrm{b}} \\
14.48^{\mathrm{c}}\end{array}$ & $\begin{array}{c}6.62^{\mathrm{b}} \\
13.40^{\mathrm{c}}\end{array}$ \\
\hline for Epeak=30 MV/m [MeV] & 0.63 & 0.78 \\
\hline Optimal beta & 0.20 & 0.20 \\
\hline
\end{tabular}

\footnotetext{
${ }^{a}$ Assuming a residual resistance of $10 \mathrm{n} \Omega$

${ }^{\mathrm{b}}$ Lacc=iris-to-iris length $=0.084 \mathrm{~m}$ and

${ }^{c}$ Lacc $=\beta \lambda$ length $=0.170 \mathrm{~m}$
} 
In general, we found Bpeak values 11\% lower with MWS than with MAFIA, which gives a dissipated power value about 21\% lower with MWS. Thus, this could be one of the reasons to explain these discrepancies but that must be checked more precisely.

\section{Tests@300K}

The cavity was delivered in December 2004 without its Helium tank and firstly tested at $300 \mathrm{~K}$. No leaks were detected under vacuum and we checked the mechanical behaviour of the new stiffening system. As shown in the Table 2, the displacements and the frequency shift of the cavity were in good agreement with those expected.

Table 2: Mechanical parameters of the cavity a under vacuum load.

\begin{tabular}{|c|c|c|c|}
\hline & \multicolumn{2}{|c|}{ Beam tubes free } & Beam tubes free \\
\hline & Ansys $^{*}$ & Cosmos & $\begin{array}{c}\text { Measurements } \\
\text { @ 300K }\end{array}$ \\
\hline $\begin{array}{c}\text { Max displacement } \\
\text { (mm) }\end{array}$ & 0.14 & 0.18 & 0.17 \\
\hline $\begin{array}{c}\text { Max Von Mises } \\
\text { stress (MPa) }\end{array}$ & 43.8 & 38.7 & N/A \\
\hline $\begin{array}{c}\text { Frequency shift } \\
(\mathrm{kHz})\end{array}$ & -378.7 & N/A & -440 \\
\hline
\end{tabular}

${ }^{*}$ Calculations performed by Evgeny Zaplatin (FZJ)

Then, we measured the thickness of the cavity walls (after a chemistry treatment of $140 \mu \mathrm{m}$ ) on 20 points of 16 profiles. The Figure 2 shows the mean value on a profile. One can notice that the thickness is locally close to $2 \mathrm{~mm}$ (instead of $3 \mathrm{~mm}$ initially)! As we will see, this thickness reduction has a big effect on the static Lorentz force detuning factor.

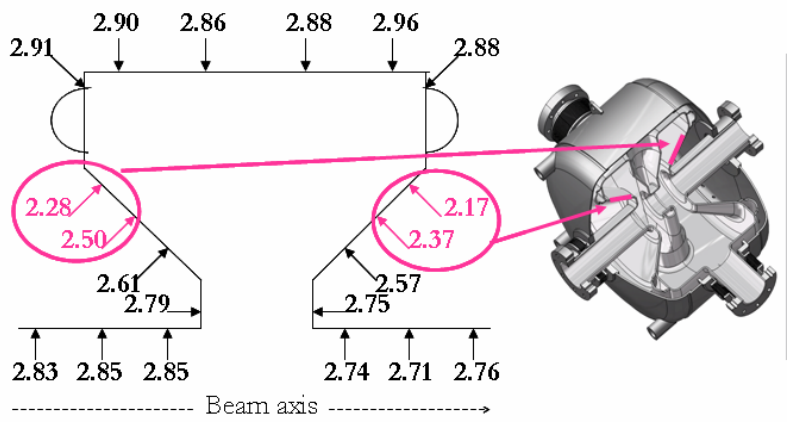

Figure 2: Average thickness in mm.

\section{Test@4.2K and 2 K}

The cavity preparation has been done at CEA/Saclay. $140 \mu \mathrm{m}$ were removed (BCP) and the cavity was rinsed through its 4 ports during 2 hours (HPR of 80 bars).

First test at $4.2 \mathrm{~K}$ has needed a 2-hour RF conditioning process to reach 9.6 MV/m $\left(\mathrm{P}_{\text {cavity }}\right.$ dissipated max $=15$ $\mathrm{W}$ ). The limitation was due to a quench (Figure 3). Two multipacting (MP) barriers were observed at $1.5 \mathrm{MV} / \mathrm{m}$ and around $8 \mathrm{MV} / \mathrm{m}$ but easily processed within a few minutes. X-ray emission started from $4 \mathrm{MV} / \mathrm{m}$ during the $1^{\text {st }}$ test then nothing after that (during the $2^{\text {nd }}$ and $3^{\text {rd }}$ tests).
We saw also a quench during the test at $2 \mathrm{~K}$ for Eacc $\max =10.5 \mathrm{MV} / \mathrm{m}\left(\mathrm{P}_{\text {cavity }}\right.$ dissipated $\left.\max =8 \mathrm{~W}\right)$. The same MP barrier at $8 \mathrm{MV} / \mathrm{m}$ has been observed but without X-ray emission.

As the quench levels are the same, i.e. for Bpeak $~ 70$ $\mathrm{mT}$, one can suspect a big defect (around Ø100 $\mu \mathrm{m}$ ) on the RF surface. We plan to remove at least $200 \mu \mathrm{m}$ more for the next test, hoping to remove this defect.

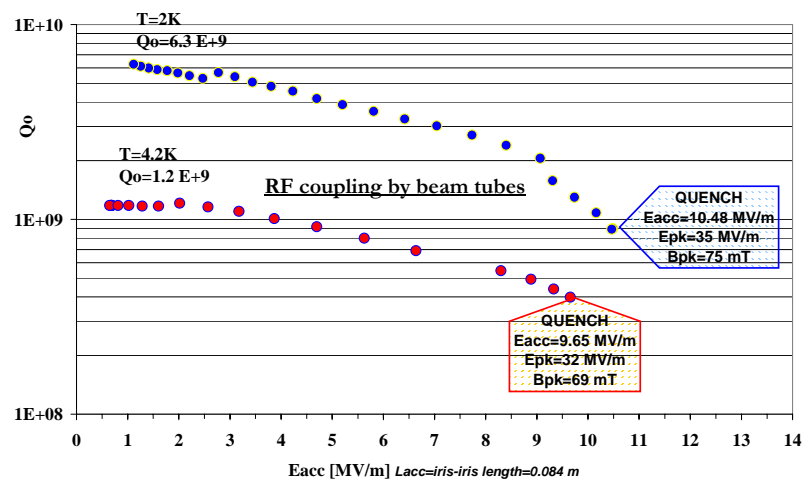

Figure 3: Cold tests results: Qo vs. Eacc

\section{Lorentz force detuning}

The cavity was tested in vertical cryostat with its beam tubes "free" (no external stiffening system was used as during the beta 0.35 spoke cavity tests).

The static Lorentz force detuning factor was measured twice: $K_{\text {Lorentz measured }}=-55$ and $-47 \mathrm{~Hz} /(\mathrm{MV} / \mathrm{m})^{2}$. As illustrated in Figure 4, Evgeny Zaplatin has shown the effect of a thickness reduction of the spoke cavity walls. One can see a good correlation with these calculated values for a cavity walls thickness between 2 and $2.5 \mathrm{~mm}$.

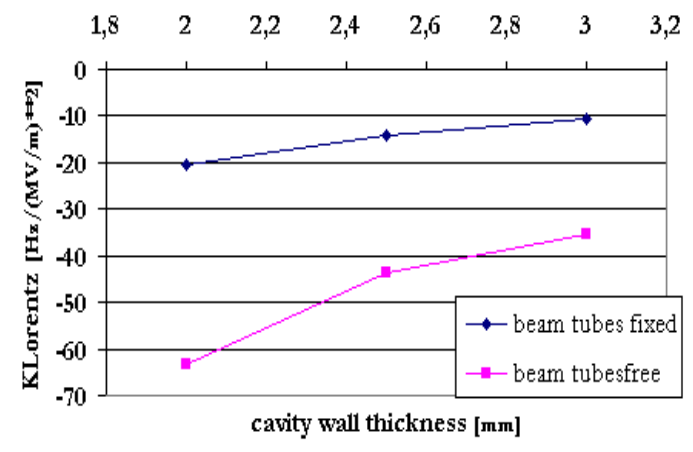

Figure 4: The static Lorentz force detuning factor vs. the spoke cavity walls thickness.

\section{BEAM DYNAMICS CONSIDERATIONS}

Spoke cavities can be very efficient in a broad intermediate velocity region, from roughly $\beta=0.1$ to $\beta=0.6$. Moreover, these cavities are short and modular, and can be very attractive, when independently powered, to accelerate several q/A ions in the same linac, like in the EURISOL case [5], or to improve the linac global 
reliability using a fault-tolerance strategy, like in the EUROTRANS case [6].

\section{Spoke cavities for EURISOL}

The EURISOL driver accelerator has to accelerate protons up to $1 \mathrm{GeV}$, but must also exhibit a strong heavy-ions capability, especially to accelerate deuteron beams [7]. In this respect, 2-gap $352 \mathrm{MHz}$ spoke cavities ( $\beta=0.15 \& \beta=0.35$ ) are proposed to cover the $5-100 \mathrm{MeV}$ proton energy range while ensuring a $50 \mathrm{MeV} / \mathrm{u}$ output energy for deuterons. In the case where the EURISOL injector operates at $176 \mathrm{MHz}$ (this choice is presently under discussion), still the second spoke section (352 MHz, $\beta=0.35$ ) would perfectly fit to the linac design.

Concerning the EURISOL post-accelerator, which has to accelerate radioactive beams in a very large q/A range up to $100 \mathrm{MeV} / \mathrm{u}, 264 \mathrm{MHz}$, 2-gap, $\beta=0.38$ spoke cavities are also good candidates for the high-energy section of such a machine, as shown in Table 3.

Table 3: Possible layout for the EURISOL postaccelerator using $264 \mathrm{MHz}$ 2-gap spoke cavities.

\begin{tabular}{|c|c|c|c|c|c|}
\hline${ }^{132} \mathrm{Sn}^{25+}$ & Section 1 & Section 2 & Section 3 & Section 4 & TOTAL \\
\hline Cavity Freq. & $88.05 \mathrm{MHz}$ & $88.05 \mathrm{MHz}$ & $176.1 \mathrm{MHz}$ & $264.15 \mathrm{MHz}$ & - \\
\hline Cavity $\beta$ & 0.07 & 0.12 & 0.24 & 0.38 & - \\
\hline \# cav./ lattice & 1 & 3 & 6 & 9 & - \\
\hline \# cavities & $12 \mathrm{cav}$ & 27 cav & 60 cav & $126 \mathrm{cav}$ & 225 cav \\
\hline Length & $13.3 \mathrm{~m}$ & $21.6 \mathrm{~m}$ & $41.7 \mathrm{~m}$ & $84.7 \mathrm{~m}$ & $161.3 \mathrm{~m}$ \\
\hline Beam energy & $\begin{array}{l}0.67 \mathrm{MeV} / \mathrm{u} \\
2.8 \mathrm{MeV} / \mathrm{u}\end{array}$ & $\begin{array}{c}2.8 \mathrm{MeV} / \mathrm{u} \\
14.3 \mathrm{MeV} / \mathrm{u}\end{array}$ & $\begin{array}{l}14.3 \mathrm{MeV} / \mathrm{u} \\
39.2 \mathrm{MeV} / \mathrm{u}\end{array}$ & $\begin{array}{c}39.2 \mathrm{MeV} / \mathrm{u} \\
100.1 \mathrm{MeV} / \mathrm{u}\end{array}$ & $\begin{array}{c}0.67 \mathrm{MeV} / \mathrm{u} \\
100.1 \mathrm{MeV} / \mathrm{u}\end{array}$ \\
\hline
\end{tabular}

\section{Spoke cavities for EUROTRANS}

The EUROTRANS project aims at demonstrating the technological feasibility of a high-power proton driver for an ADS.

The main challenge here is to reach the reliability requirement, which is extremely stringent: beam trips in excess of 1 second duration should not occur more frequently than 5 per year. To reach this goal, the proton superconducting linac must be "fault-tolerant": any individual cavity failure must be handled "on-line" at all stages without loss of the beam. This is done using the local compensation method, which principle is illustrated in Figure 5: with an appropriate retuning, beam dynamics simulations show that in every case of RF cavity failure, the beam can be transported up to the high-energy end without any beam loss. At least 30\% margins on RF power and accelerating fields are needed to carry out such a compensation [8]. In order to practically implement such a strategy, fast recovery scenarios (milli-second range) have to be set up. The use of adequate diagnostics and fast digital LLRF control systems with pre-tabulated set-points is mandatory.

The feasibility study of these transient scenarios is presently starting within the EUROTRANS project, with expected results before 2007.

\section{Cavity \#n is faulty \\ Cavities $\# n-2, \# n-1, \# n+1, \# n+2$ are retuned to recover the nominal beam energy \& phase at point $M$}

Figure 5: The "local compensation” method.

\section{CONCLUSION}

Following these good results, we will test, in 2006, the beta 0.15 spoke cavity, equipped with its Helium tank and its RF coupler, inside a horizontal cryostat, presently under development at IPN. We also plan to fabricate two new spoke-type prototypes for EURISOL and start the design of their dedicated cryomodule with a preliminary LLRF control system.

\section{ACKNOWLEDGEMENTS}

The authors want to thank E. Zaplatin from FZJ for having performed the calculations on the mechanical behaviour of the spoke cavities ... it works! We also thank P. Maccioni, M. Gauthier and M. Febvre from CERCA company, and A. Aspart, J.P Poupeau and Y. Gasser from CEA/Saclay for the preparation of the cavity. Finally, authors thank K. Shepard, M. Kelly and Z. Conway from ANL for fruitful discussions.

\section{REFERENCES}

[1] G. Olry \& al., "Development of SRF spoke cavities for low and intermediate energy linacs”, SRF2003, Lübeck, Germany, September 2003.

[2] G. Olry et al., "Recent developments on superconducting beta 0.35 and beta 0.15 spoke cavities at IPN for low and medium energy sections of proton linear accelerators”, EPAC2004, Lucerne, Switzerland, July 2004.

[3] G. Olry et al., "Development of beta $0.12,88 \mathrm{MHz}$, quarter wave resonator and its cryomodule for the Spiral2 project”, these proceedings.

[4] G. Olry et al., "R\&D on spoke-type cryomodule", EPAC2002, Paris, France, June 2002.

[5] see http://www.ganil.fr/eurisol/

[6] J-L. Biarrotte et al., “A European advanced technology programme for ADS development”, these proceedings.

[7] J-L. Biarrotte, "High power CW superconducting linacs for EURISOL and XADS”, LINAC04, Lübeck, Germany, August 2004.

[8] J-L. Biarrotte et al., "Beam dynamics studies for the fault tolerance assessment of the PDS-XADS linac design”, 33 $3^{\text {rd }}$ ICFA Advanced Beam Dynamics Workshop on High Intensity and High Brightness Hadron Beams, October 2004, Bensheim, Germany. 